\title{
1976 CURRENT INDEX TO STATISTICS
}

Many readers of the

\author{
Journal of Applied Probability
}

and

\section{Advances in Applied Probability}

and others who make substantial use of statistical methods will be interested in the 1976 edition of the Current Index to Statistics: Applications, Methods and Theory. This index provides comprehensive coverage of statistics and of statistical aspects of a variety of related fields such as biostatistics, survey methodology, econometrics, education, sociology, psychology, engineering, quality control, stochastic modelling, and so on.

Articles from the Applied Probability journals and other journals, as well as conference proceedings, monographs, research volumes and related publications, are included. Each article is indexed in several ways: by each author, by non-trivial words in the titles (KWIC), and where available, by keywords.

Prices for the 1976 Current Index to Statistics are:

Individuals: $\quad \$ 12.00$

Institutions: $\quad \$ 18.00$

Volume 1, covering 1975, is also available at the same price. Copies may be ordered from:

The American Statistical Association, 806 15th Street, N.W., Washington, D.C. 20005 , U.S.A.

Editorial information may be obtained from:

Brian L. Joiner, Editor,

Current Index to Statistics,

University of Wisconsin,

1210 W. Dayton Street, Madison, Wisconsin 53706, U.S.A. 


\title{
Publications of the Applied Probability Trust
}

\author{
Methuen's Supplementary Review Series in Applied Probability
}

General Editor: M. S. Bartlett, M.A., D.Sc., F.R.S. Editor: J. Gani, D.I.C., Ph.D., D.Sc., F.A.A.

The following titles in this series are still available; the papers appeared in the earlier volumes of the Journal of Applied Probability.
Volume 2 M. Kimura:
Diffusion models in population genetics
Volume 3 E. J. Hannan:
Group representations and applied probability
Volume 5 S. Kotz:
Recent results in information theory
Volume 6 J. F. C. Kingman:
On the algebra of queues

Price per volume: $£ 0.50$ (US\$1.25; \$A.1.00).

Proceedings of the WHO Symposium on Quantitative Epidemiology (Moscow, November 1970): reprinted from Advances in Applied Probability, Volume 3.

Price per copy: $£ 0.50$ (US\$1.25; $\$ A .1 .00)$.

\section{Proceedings of the Conference on Directions for Mathematical Statistics}

held at the University of Alberta, Edmonton, Canada, 12-16 August 1974.

This title was issued as a special supplement to Adv. Appl. Prob. Volume 7 No. 3.

A limited number of copies are still available at the price of $£ 2.30$ (US\$4.00; \$A3.70).

Orders for the above should be sent to

Applied Probability, Dept. of Probability and Statistics,

The University, Sheffield S3 7RH, England.

All orders should be accompanied by a remittance, payable to 'Applied Probability'.

\section{Mathematical Spectrum: A magazine of contemporary mathematics}

This magazine addresses itself primarily to young mathematicians in schools, colleges of education and universities. Its object is to discuss the entire range of modern mathematical disciplines in an informative but informal manner and to relate discoveries in mathematics to progress in the natural sciences, technology, social studies and business management.

The Editors believe that the process of learning is a dialogue and consequently they wish to promote active participation by readers. Correspondence on any subject relating to mathematics and mathematical education is welcomed. There is also a problem section, and readers are encouraged to submit their solutions, the best of which are published.

For further information and a detailed price list application should be made to

Editor - Mathematical Spectrum (Ref. AP)

Hicks Building, The University,

Sheffield S3 7RH, England. 


\section{Advances in Applied Probability}

The Editorial Board would like to encourage the submission to the Advances of Review Papers summarising and coordinating recent results in any of the fields of Applied Probability.

In addition to these review papers, Advances is also designed to be a medium of publication for (1) longer research papers in Applied Probability, which may include expository material, (2) expository papers on branches of mathematics of interest to probabilists, (3) papers outlining areas in the biological, physical, social and technological sciences in which probability models can be usefully developed, and finally, (4) papers in Applied Probability presented at conferences which do not publish their proceedings.

In short, the main function of Advances is to define areas of recent progress and potential development in Applied Probability. As with the Journal of Applied Probability, Advances undertakes to publish papers accepted by the Editors within 15 months of their submission.

The Editorial Board consists of E. Sparre Andersen, V. D. Barnett, D. Blackwell, V. R. Cane, J. W. Cohen, B. Gnedenko, E. J. Hannan, C. C. Heyde, J. Keilson, D. G. Kendall, J. F. C. Kingman, K. Krickeberg, R. M. Loynes, P. A. P. Moran, J. Neveu, K. R. Parthasarathy, N. U. Prabhu, R. Pyke, C. A. B. Smith and L. Takács. The Editor-in-chief is J. Gani, and the Editorial Office of the Advances is in the Department of Probability and Statistics, The University, Sheffield S3 7RH, England.

Volume 9 No. 3 of Advances contains the following papers:

\section{BUFFON BICENTENARY SYMPOSIUM ON \\ Lake Sevan, Erevan, Armenian SSR 13-18 September 1976} STOCHASTIC GEOMETRY AND DIRECTIONAL STATISTICS M.J. FADDY

JOEL E. COHEN

D. K. PICKARD JAN GRANDELL JEFFREY J. HUNTER

\section{HARRY COHN}

JOHN RICE

PRISCILLA GREENWOOD AND MOSHE SHAKED

A. BADDELEY

MARCEL F. NEUTS an example Asymptotic inference for an Ising lattice. II

Point processes and random measures function behaviour

On generalized shot noise

Stochastic compartmental models as approximations to more general stochastic systems with the general stochastic epidemic as

Ergodicity of age structure in populations with Markovian vital rates, III: Finite-state moments and growth rate; an illustration

Renewal theory in two dimensions: bounds on the renewal

Countable non-homogeneous Markov chains: asymptotic

Fluctuations of random walk in $R^{d}$ and storage systems

Integrals on a moving manifold and geometrical probability The $M / G / 1$ queue with several types of customers and changeover times

Stationary distributions for dams with additive input and contentdependent release rate

Subscription rates (per volume) for the Advances in 1977 are the same as for the Journal (see inside back cover). A discount of $10 \%$ is allowed to subscribers who order current issues of both the Journal and Advances at the same time direct from the Applied Probability Office. A detailed price list for both current and back issues is available on request.

Cheques made out on U.S., U.K. and Australian banks will be acceptable: they should be made payable to Applied Probability, and sent to:

Executive Editor, Applied Probability,

Department of Probability and Statistics,

The University, Sheffield S3 7RH, England. 


\section{Subscription rates}

Subscription rates (post free) for the 1977 volume of the Journal are as follows:

Subscribers in North, Central and South America, and Australia:

U.S. $\$ 60.00, \$ A .45 .00, £ 30.00$ for libraries and institutions;

U.S. $\$ 20.00, \$ A .15 .00, £ 10.00$ for individuals belonging to a recognised scientific society.

\section{All other subscribers:}

$£ 24.00$ for libraries and institutions;

$£ 8.00$ for individuals belonging to a recognised scientific society.

Members of the London Mathematical Society should apply direct to the Secretary of the Society for copies of the Journal.

All enquires about the Journal, as well as other subscriptions, should be sent to the Executive Editor, Miss M. Hitchcock, Department of Probability and Statistics, The University, Sheffield S3 7RH, England. The price of back numbers varies from volume to volume, and enquiries should be sent to the Executive Editor. Cheques, money orders, etc., should be made out to Applied Probability; cheques on U.S., U.K. and Australian banks will be acceptable.

\section{Notes for Contributors}

Submission of papers. It is a condition of publication in the Journal of Applied Probability that papers shall not previously have appeared elsewhere, and will not be reprinted without the written permission of the Trust. The copyright of all published papers shall be vested in the Trust. It is the general policy of the Journal not to accept for publication papers which cannot appear in print within 15 months of their date of submission. Authors will receive 50 reprints of their papers free, and joint authors a proportional share of this number. Additional reprints will be provided at cost.

Manuscripts should be written in English or French; manuscripts in other languages may be accepted by the Editors, but will appear (subject to the author's agreement) in English or French translation in the Journal. Authors are requested to comply with the following instructions in submitting their papers:

Authors in Britain, Europe, North and South America should send three copies of their submissions to the Applied Probability Office in Sheffield.

Authors in Australasia and the Far East should send three copies of their submissions to the Editor-inChief, Dr. J. Gani, in Canberra.

The Editor-in-Chief and the Applied Probability Office are in direct contact by Telex, and full details of the papers submitted either in Sheffield or Canberra are available in both centres.

Alternatively, authors may submit papers to any of the Editors listed on the inside front cover. In this case, two copies of the submission should be sent to the Editor concerned, and one copy, with a copy of the covering letter, should be sent to the Applied Probability Office in Sheffield.

Journal conventions. It will be of help to the Editors if the following conventions are adopted:

a) The manuscript should be typewritten, using double spacing, on one side of the paper only.

b) Each paper submitted should be accompanied by

(i) a short abstract of approximately 4-10 lines giving a non-mathematical description of the subject matter and results;

(ii) a list of keywords detailing the contents for the purpose of computerised information retrieval.

c) References should be indicated in the text by the name of the author(s) and the date, thus: Feller (1961), and the full references listed at the end of the article in alphabetical order. Journal references should include the title of the article cited, the title of the journal (abbreviated in the style of the International Journal of Abstracts: Statistical Theory and Method), the volume, and inclusive page numbers. Book references should give the full title, the publisher, and the place of publication. For example:

Feller, W. (1961) A simple proof of renewal theorems. Comm. Pure Appl. Math. 14, $285-293$. Robinson, E. A. (1959) An Introduction to Infinitely Many Variates. Griffin, London.

d) Type faces should be carefully distinguished on the manuscript using the following standard methods of marking:

Italics capitals $(T, I, R)$ and lower case letters $(t, i, r)$ should be underlined once, e.g. $\underline{\mathbf{T}}, \underline{\mathbf{I}}, \underline{\mathbf{R}}, \underline{\mathrm{t}}, \underline{\mathrm{i}}, \underline{\mathrm{r}}$. Bold-face capitals $(\mathbf{T}, \mathbf{I}, \mathbf{R})$ and lower case letters $(\mathbf{t}, \mathbf{i}, \mathbf{r})$ should have a curly underline, e.g. T, I, R, t, i, r. Greek characters $(\alpha, \beta, \theta)$ and script letters $(\mathscr{J}, \mathscr{I}, \mathscr{R})$ should be carefully drawn and identified when first used by a marginal note of the form ' $\alpha$-lower case Greek alpha' or ' $\mathscr{R}$-script R'.

e) Indices and subscripts should be clearly distinguished, using the marking $\stackrel{4}{4}$ where necessary.

Authors will receive only first proofs for correction; charges will be made for excessive alteration to these.

Printed in Israel at the Jerusalem Academic Press, P.O.B. 2390, Jerusalem. 


\section{CONTENTS}

\section{Number 3}

September 1977

\section{Volume 14}

I. B. GERTSBAKH

STANLEY SAWYER

P. J. GREEN

C. D. LAI 46

VIOLET R. CANE 475

B. D. RIPLEY AND 483

J.-P. RASSON

BENNY LEVIKSON

VALERIE ISHAM 507

W. REH 516

T. S. LEE AND F. KOZIN

NANCY L. GELLER 538

M. MIURA 548

J. C. GITTINS AND 556

K. D. GLAZEBROOK

J. MICHAEL HARRISON 566

AND AUSTIN J. LEMOINE

J. F. C. KINGMAN

F. P. KELLY

ERIC RENSHAW

RICHARD W. KATZ

CHARLES M. GOLDIE

ALEXANDER MEHLMANN

DAVID B. WOLFSON

A. O. PITTENGER

KNUT K. AASE

J. D. BIGGINS

MARK WESTCOTT

D. N. SHANBHAG

HAROLD RUBEN

J. E. MANN 654
Research Papers

Epidemic process on a random graph: some preliminary results

39 On the past history of an allele now known to have frequency $p$

Conditional limit theorems for general branching processes A two-dimensional 'immigration-branching' model with application to earthquake occurrence times and energies A class of non-identifiable stochastic models

Finding the edge of a Poisson forest

The age distribution of Markov processes

A Markov construction for a multidimensional point process

Generalizations of the elementary renewal theorem to distributions defined by concave recurrence relations

Almost sure asymptotic likelihood theory for diffusion processes

On limit distributions for one- and two-sample Kolmogorov-Smirnov type statistics

Stochastic analysis of the raw silk reeling process

On Bayesian models in stochastic scheduling

Limit theorems for periodic queues

\section{Short Communications}

577 Remarks on the spatial distribution of a reproducing population

584 The asymptotic behaviour of an invasion process

591 Velocities of propagation for stepping stone models of population growth

598 An application of chain-dependent processes to meteorology

604 Lanchester square-law battles: transient and terminal distributions

611 A note on the limiting behaviour of discrete-time Markovian manpower models with inhomogeneous independent Poisson input

614 Limit theorems for sums of a sequence of random variables defined on a Markov chain

A note on the inverse problem for reducible Markov chains

626 A conditional expectation formula for diffusion processes

630 Chernoff's theorem in the branching random walk

637 A note on record times

640 An extension of the Rao-Rubin characterization of the Poisson distribution

647 The volume of a random simplex in an $n$-ball is asymptotically normal

On the length distribution of stochastic subarcs of a rectifiable arc 